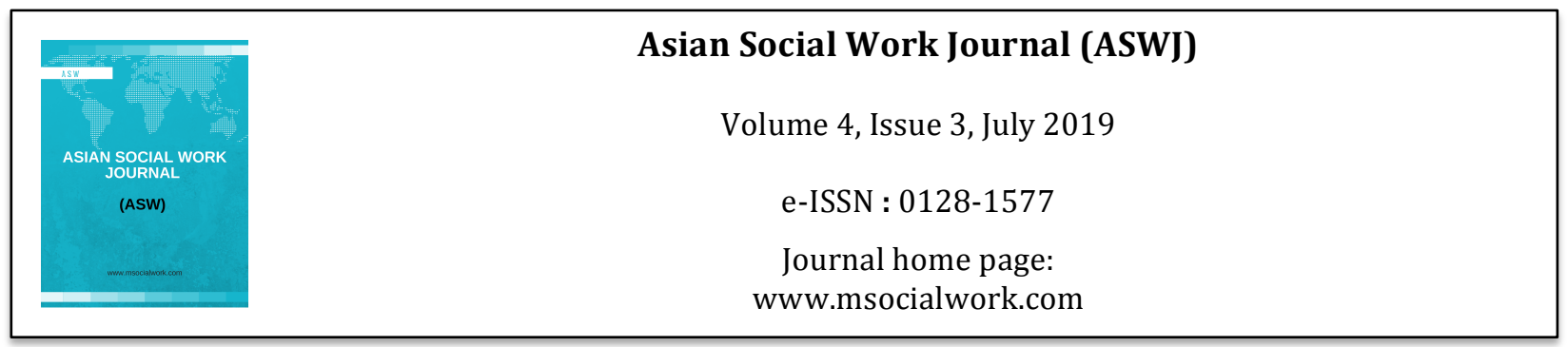

\title{
Emotional Coping Through Solution Focused Counselling Therapy: Case Study of Psychological Distressed Women
}

\author{
Nurul Naimah Rose ${ }^{1}$, Aida Shakila Ishak ${ }^{1}$ \\ 1University Malaysia Perlis \\ Corrrespondence: Nurul Naimah Rose (naimahrose@unimap.edu.my)
}

\begin{abstract}
The aim of this paper was to explore the emotional coping of psychological distressed women who had undergone counselling session based on Solution Focused Therapy Module. Six (6) working women were selected as subjects based on the criteria such as currently working and have had experience symptoms of psychological distress such as anxiety and depression for the past four weeks. The subject's levels of psychological distress were measured using the Kessler psychological distress scale (K10). In this study, qualitative case study method had been done to get in depth understand of the emotional coping styles among the subjects. The pre and post interviews had been conducted with all the subjects to explore how they cope emotionally with the psychological distress before and after the intervention. Finding of this research explained that subjects had a different style of emotional coping before and after the intervention. The subjects agreed that their type of emotions influenced the level of psychological distress. Before the intervention, subjects experienced negatives emotions that influenced them to have negative styles of emotional coping such as withdrawal, over thinking, problem avoidance and crying. After the intervention subjects experienced positive emotions that made them to be calmer and relax, they also felt better and able to think of the solutions to their problems. Thus, they need to be able to control their emotion prior to reducing the level of psychological distress. Subjects also have different coping mechanism before and after the intervention due to their age differences and maturity level.
\end{abstract}

Key words: emotional coping, psychological distress, solution focused therapy, working women

\section{Introduction}

Psychological distress can be understood as a term to describe unpleasant feelings or emotions that affect the level of functioning for individual (Mirowsky \& Ross, 2003). The unpleasant feelings and emotions occur to individual with too many issues and problems which unsuccessfully resolved. Individual tend to ignore the issues and problems rather than trying to find solution to solve the problems. Then, it creates series of unresolved problem which contributes to the psychological distress experience. Women in general are the most frequent experiencing high level of psychological distress (Mirowsky \& Ross, 2003). This is due to various roles as a wife, a mother and also an organization's employees. Women experiencing high level of psychological distress have the tendency to feel unhappy, sad, frustration, anxiety and depressed which lead to low level of satisfaction in life (Umi Adzlin S, et al., 2011).

Psychological distress affects many aspects in women's live such as emotion, psychology, cognitive and physiology. Among those aspects, the emotion aspect is the most affected by psychological distress 
(Kendall-Tackett, 2005). Women often lost control of their own emotion and they rather let themselves to occupy by their emotional state. When the level of psychological distress is high, they will experience negative types of emotion (Noor, 2002). It will appear as symptoms to identify the occurrence of psychological distress. The negative emotions include unpleasant, frustration, irritable, worry, anxious, sad and anger.

From a mental health perspective, women are very synonymous with mental health and disorders (Fisher, Astbury, de Mello, \& Saxena, 2009). Women dominate the high levels of mental disorders such as depression, emotional distress, anxiety, anger and sadness (Simon \& Nath, 2004). There was a study that proved the working wives experienced high level of distress and depression twice as high compare to the husbands (Umi Adzlin S, et al., 2011). This is due to various factors including biological, socio-economic factors and other unpredictable factors such as communication style. Therefore, women need to be helped with appropriate therapy to reduce their level of psychological distress as well to improve their quality of lives.

The Solution Focused Therapy was developed by Steve de Shazer and In Soo Kim Berg which can be applied to help client working with their stress and depression (Lipchick, 2002). The therapy gives special attention on solving problems and making changes by acting positively and rationally (Sklare, 2005). The positive thinking style applied during counseling sessions also helps women to have a sense of self control towards their emotions (Johnson, 2009). Thus, it help to reduce the level of psychological distress by minimize the symptoms.

Solution focused therapy use different treatment approaches from other therapies in counseling. Other therapies build counseling goals to understand and identify client problems. But solution focused therapy put focus on finding a solution based on the resources available to the client (de Shazer \& Dolan, 2007). Solution focused therapy believes that the problem does not occur all the time. Therefore, clients need to put themselves in a situation without problem to build a solution. Clients who are experiencing psychological distress often have negative thinking styles. Hence, this therapy helps clients to have positive emotions and able to think positively (Miller \& de Shazer, 2004).

\section{Study objectives}

Purpose of this research is to understand the emotional coping strategy of women experiencing psychological distress who undergone solution focused therapy as a treatment. The ability to cope and control emotion is important to help reducing the level of psychological distress among working women. Solution focused therapy was used as a tool to explore the psychological distress experience and as well to understand the coping strategy. Furthermore, the therapy helps to educate women the appropriate skill to control their emotion while experiencing distress in any situation.

\section{Literature Review}

Since the mid 1980's, previous studies have shown that Solution Focused Therapy had a positive impact on clients experiencing psychological distress. Many studies conducted shows that Solution Focused Therapy effectively helping to reduce the symptoms and distress levels of clients from different backgrounds. (Jaseem Koorankot, Tilottama Mukherjee, \& Ashraf, 2014; Bond, Woods, Humphrey, Symes, \& Green, 2013; Castaldo, 2008; Smock, et al., 2008; Crockett \& Prosek, 2013; Estrada \& Beyebach, 2007 \& Pashapu Dharma Reddy, Ammapattian Thirumoorthy, Poreddy Vijayalakshmi, \& Mohammed Ameer Hamza, 2017).

Solution Focused Therapy able to give a positive impact to the client because the objective of counseling session is the client's changes in the emotions, thoughts and behaviors. The role of counselors is also important to build a positive environment for clients to make changes. Counselors play a role in encouraging clients to keep changing. Consequently, Solution Focus Therapy help clients to feel more positive emotions and thoughts so that the level of distress could be reduce. Client's 
change is the most crucial in Solution Focused Therapy. To ensure continues changing, counseling session talks more about solution not the problem.

The study of women and stress in Malaysia refers to the involvement of women in the employment sector, the role of women in the family, single mothers and health problems, conflicting role of women as workers and at the same time as wives and mothers. In addition, studies on discrimination against working women have been conducted and the finding suggested that stress occur when women were not given the same opportunities as men in terms of career development (Faatin \& Norashikin, 2014). Other studies conducted such as women who work as teachers (Azlihanis Abdul Hadi, Nyi Nyi Naing, Aziah Daud, Rusli Nordin, \& Mohd Rahim Sulong, 2009) and manager in industry (Amat, Fontaine, \& Chong, 2003). Based on the following study, women in Malaysia experiencing stress due to long hours of work, need to work on shift schedules, overloaded workloads, household conflicts, motherhood responsibilities, relationship with friends, long-distance marriage relationships as well as role of single mothers (Noor Rahamah Hj Abu Bakar, 2012).

Married women who are working usually need to do the job as a worker and wife or mother at the same time (Noor, 2002). Therefore, they need to balance the role to fulfill their responsibility as a wife, a mother and a worker. It becomes a challenge whereby women who work full time also serve as full time housewives. The responsibility adds on too much pressure for women due to lack of time and they became fatigue after doing their work at the office and later at home (Noor, 2003).

Society has viewed that every woman must be a perfect wife and a mother even though they have to work full-time (Noor, 1999). Therefore, women usually do not express the burden they face in order to avoid being labelled as a failing wife (Noor, 1999). However, some women do appreciate the help given by the couple in household affairs (Lestari, 2000). In addition to that, the stresses were higher among the single mothers due to lack of spouse's support (Noor Ba'yah \& Bifulco, 2011).

As compared to men, women have the tendency to react more to negative emotions. Research in psychology suggested that men suffer more stress due to their coping style which is more emotion oriented. Psychology sees women as an emotional complex being (Kendall-Tackett, 2005). Thus, woman prefers to indulge themselves in variety and complex types of emotions. Therefore, their emotion has great impact on everything that their do in life. It even takes control of their behavior, thinking styles, communication styles, morality and values and in making decision. In dealing with distress, women tend to really feel the emotions and they would mingle themselves with all the negative emotions. Often distress women would have more than one emotion at the same time. It creates confusion and become a barrier for them to find solution to their problems.

\section{The Pearlin Psychological Distress Theory}

Pearlin defined distress as a stimulus that leads to psychological responses (Mirowsky \& Ross, 2003). The Pearlin Psychological Distress Theory explained that human gained maturity throughout their lives after been through the pressure of life challenges (Pearlin, 1989). Based on this theory, human development is continuously occurring without any stages. Pearlin described from sociological perspective that environment plays an important role in individual's self-development. The distress process refers to the stress factor and the method of dealing with it. Therefore, due to the different method of dealing with stress, each individual would have different experience.

According to Pearlin's theory of psychological distress, there are four (4) important elements that influence individual self-development; i) Personality that includes individual features such as gender, race, education background, family, intellectual and cultural levels. The diversity of these features will affect the level of individual distress. ii) Coping mechanism that refers to individual skills in managing distress. iii) Social support that is needed for individual to help dealing with distress. Social support includes families, spouses, close relatives and friends. iv) Situations and times when psychological distress occurred and it requires appropriate response. Pearlin thinks that individuals in their early adulthood experience psychological distress because they need to take responsibility such as 
commitment to new jobs and marriages. However, individuals have their own right to plan their life according to their wants.

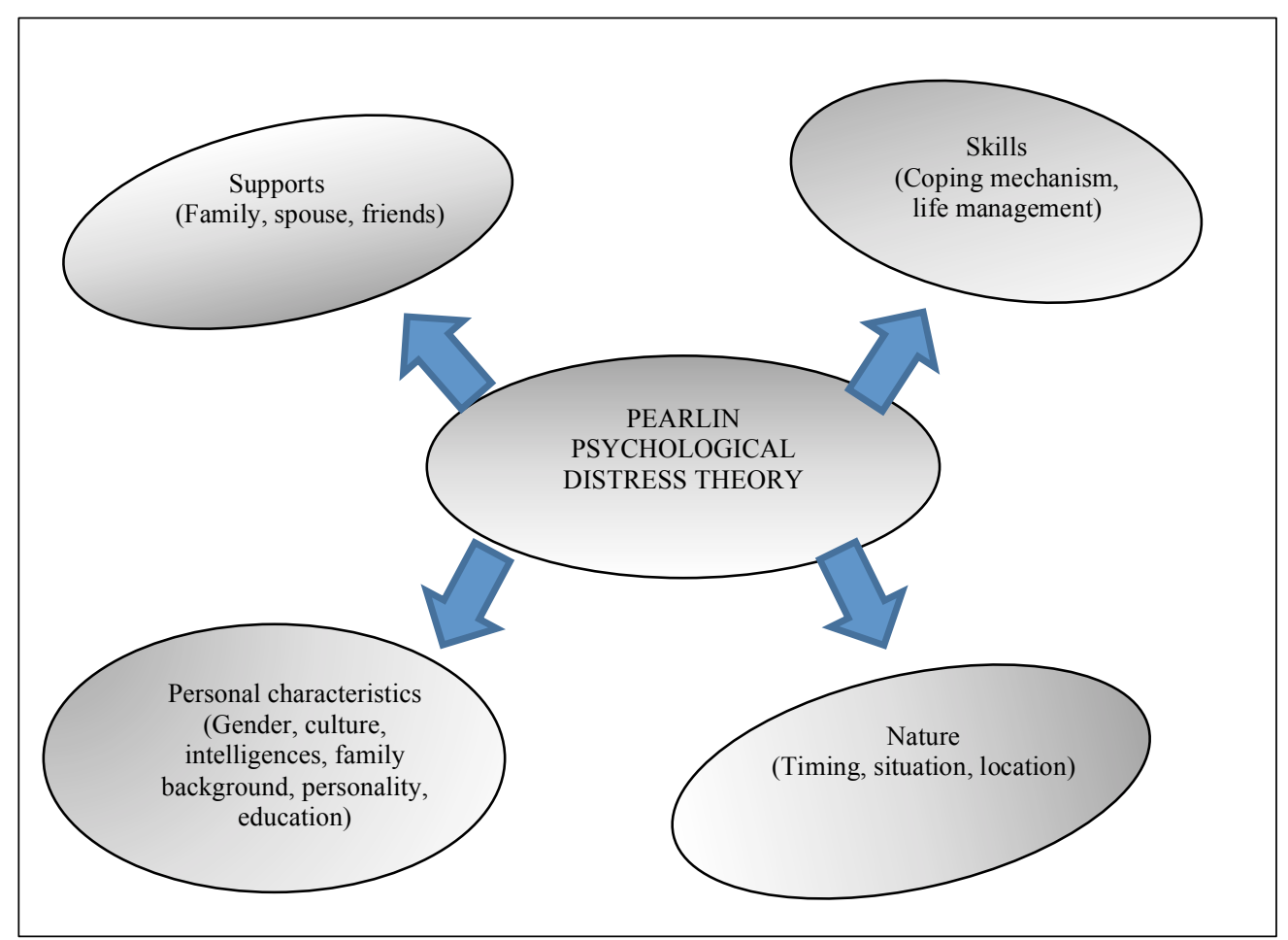

Sources: Mirowsky \& Ross, 2003

Figure 1: Pearlin Psychological Distress Theory

\section{Methodology}

\section{Qualitative Case Study method}

This study used qualitative methods as it helps the researcher to understand more deeply about the experience, meaning and process that the subjects had been through (Silverman, 2010). This study focused on deeply understanding the emotional coping of psychological distressed women who undergone counselling session based on the solution-focused therapy. This study was inductive in nature as it developed concepts and categories based on the phenomena through data that was collected during study. Researchers also did interpretation and add their own perspectives based on the experiences during the field study to gain a holistic understanding of the phenomena.

\section{Study sample}

This study chooses non-probability sampling technique which involving sample selection based on the criteria set prior to data collection. Non-probability type sampling is suitable for this study because the aim of this study was not to generalize the finding to a larger population (Yin, 2014). However, the selected sample as a subject had relevant experience and able to provide adequate information about the phenomena.

Figure 2 shows the sampling technique used. Researchers began to select subjects using convenience and purposive sampling techniques to ensure that the selected subjects met the criteria. By using convenience and purposive sampling techniques, researches managed to obtain only one subject. Then, 
researchers used snowball sampling techniques to get more subjects until the total number of subjects was sufficient for this study.

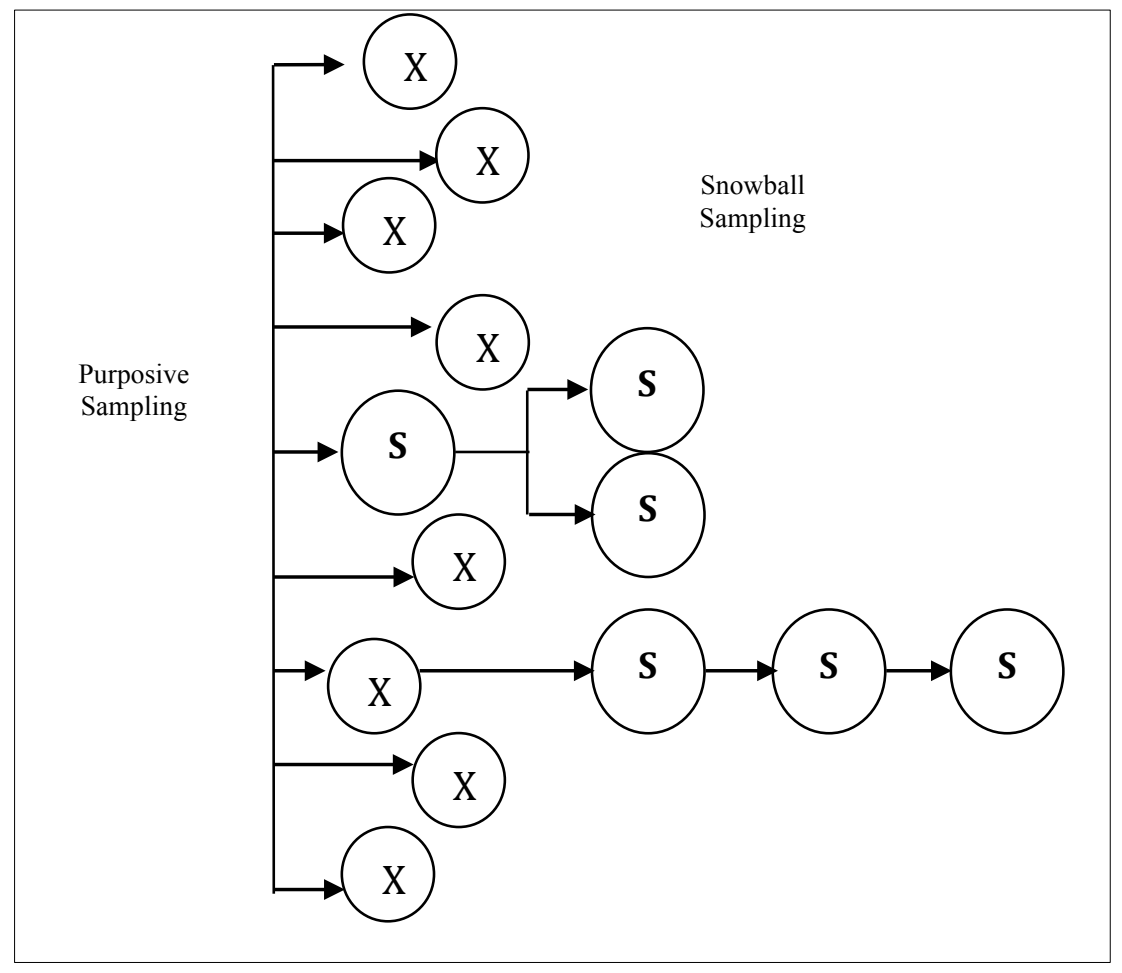

Figure 2: Sampling technique

There are three (3) types of sampling techniques used in this study as the method of selecting the subject; i) purposive sampling, ii) convenience sampling, and iii) snowball sampling (Creswell, 2009). The purposive sampling technique was used to select the most suitable subjects that meet the criteria to be studied. The researchers set some criteria for the selection of subjects based on the objective of the study and the literature review.

The researcher listed six (6) criteria for women aged 20 to 40 years old, currently working, experiencing some of the symptoms of psychological distress such as depression and anxiety, does not have a serious mental or psychological disorder, not under influenced of drugs or alcohol and most importantly agree to become participated in this study willing to undergo six (6) counselling intervention sessions.

\section{Research instrument}

Interviews were conducted to collect information on facts, experiences, beliefs, feelings, views and values to find answers to the research questions (Rubin \& Rubin, 1995). Researchers used semi structured interview questions as they are more open and flexible to any changes according to the circumstances during the interviews (Cohen, Manion, \& Morrison, 2007). It helped the researchers to get adequate information from the subjects. Furthermore, if necessary more questions can be added later.

\section{Data analysis}

Researchers did the analysis using interactive data analysis techniques; 1) data collection, 2) data reduction, 3) data presentation, 4) conclusion / verification (Miles \& Huberman, 1994). 


\section{Study Results}

Analysis case shows that subjects in this study were individuals from 24 to 40 years old. Two subjects work as teachers while four other subjects work as lecturers. Three subjects were married and three subjects were single. All selected subjects represent different levels of age and have their own views on the issues being studied. Hence, the data obtained constitute a distinctive theme to answer the research questions.

Table 1. Subject's Demographic Background

\begin{tabular}{|c|c|c|c|c|c|}
\hline & Age & Status & Occupations & Experiences & Issue \\
\hline Subject 1 & 26 & Single & Teacher & $\begin{array}{l}1 \text { year } 6 \\
\text { months }\end{array}$ & Workload \\
\hline Subject 2 & 24 & Single & Teacher & 1 year & Financial \\
\hline Subject 3 & 39 & Married & Lecturer & 14 years & Relationship \\
\hline Subject 4 & 29 & Married & Lecturer & 6 years & Anxiety \\
\hline Subject 5 & 40 & Single & Lecturer & 16 years & Loneliness \\
\hline Subject 6 & 29 & Married & Lecturer & 4 years & Workload \\
\hline
\end{tabular}

Various issues had been brought up during the sessions such as excessive burden of work, financial problems, relationship problems, excessive anxiety and loneliness. These issues become the factors in which the subjects experiences psychological distress. In addition, the subject also mentioned about other contributing factors such as health problems and self-conflicts. Result of this study can be elaborated based on the emergence categories and themes.

\section{Coping Mechanism}

Coping mechanism is the respond behaviour in situations of psychological distress. Individual in distress have their own way of responding to distress situation. The researcher aim was to understand the subject's subjectivity of emotional coping mechanism when they experiencing psychological distressed. Researchers also put focus on subject's effort to reduce, prevent or control the unpleasant effects of psychological distress. Findings of this study will be reported based on the emergence themes which is coping mechanism before and after the intervention.

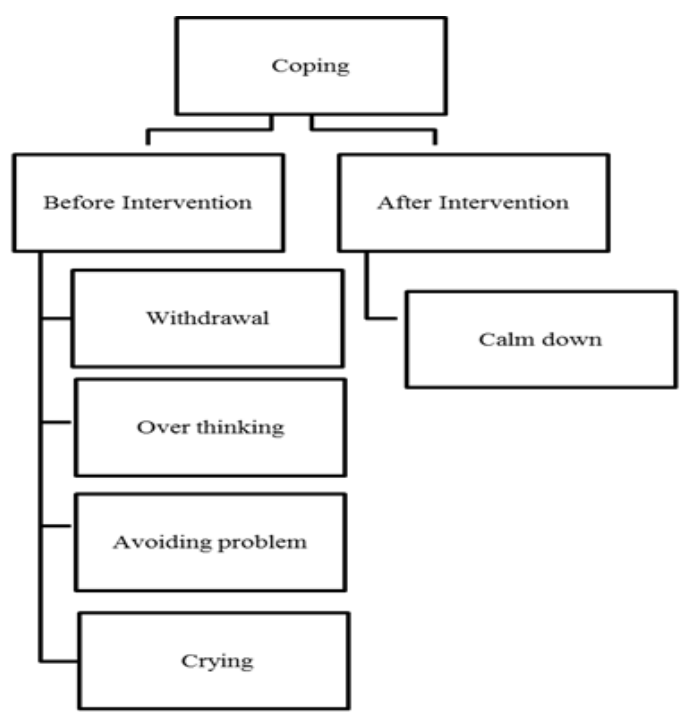

Figure 3: Coping Mechanism among Subjects 
Table 2. Theme and Subtheme for subjects coping mechanism

\begin{tabular}{llc}
\hline Theme & Sub theme & Subjects (n) \\
\hline Coping mechanism & Withdrawal & 1 \\
before intervention & Over thinking & 3 \\
& Avoiding Problem & 2 \\
& Crying & 2 \\
$\begin{array}{l}\text { Coping mechanism } \\
\text { after intervention }\end{array}$ & Calm down & 4 \\
\hline
\end{tabular}

Figure 3 and Table 2 shows a summary of the theme, subtheme and number of subjects for coping mechanism. There are emergence themes which are before the intervention and after the intervention. Coping mechanism before the intervention, there are four sub themes namely withdrawal $(\mathrm{n}=1)$, crying $(n=2)$, over thinking $(n=3)$ and avoiding problems $(n=2)$. While there is one theme for coping mechanism after the intervention which is calm down $(n=4)$.

\section{Emotional Coping Mechanism before Intervention}

Through the first interview transcript analysis, the subject coping mechanism can be described in two situations. The first coping mechanism is before subjects undergo the counselling intervention. The second coping mechanism is after the subjects undergo the counselling intervention. This study found out that there is a difference coping mechanism used by the subject before and after the intervention. This is mostly because during the counselling intervention, subjects have received information on the methods of controlling emotions during distress. The subjects also mentioned that they had better understanding of distress after went through the intervention.

The first subtheme before the counselling session is withdrawal. When psychological distress occurs, subject becomes confused due to the various emotions that felt simultaneously and mix up to one another. For instance, subject 1 feels sad and angry at the same time when experiencing distress. Therefore, subject 1 wanted to withdraw herself from others. The confusion causes the subject to focus on emotions rather than taking action to solve the problems. In a condition of emotionally unstable, the level of psychological distress getting higher and it the effect is worsen.

I feel like I'm confuse ... I feel like I'm so mad... I feel like I want to do this... in this situation... I just do not like to sit close to people ... if I in the middle of the crowd... I would be silent ... when I'm at home... emm ... I would stay in the room ... locked... I would stay away from people...

(Subject 1)

The second subtheme is over thinking where subject thinking too much when experiencing distress. This happened to subject 5 when she started to think of ways to reduce stress but she failed to find the right solution. Thus, she became fatigue when she could not stop thinking and it affects her life quality. She mentioned that she felt like carrying a heavy burden on her shoulder.

I would think and think and think... as long as it does not settle... I would think and think... I feel like there is heavy burden on my shoulder that I could not let go.

(Subject 5)

Meanwhile, Subject 2 mentioned that due to over thinking resulted to tiredness and fatigue. Furthermore, mind becomes more irrational where she often think to run away just to calm her feelings. In addition to that subject also trying to comfort her self by saying that the problem is just temporary. So, she can just ignore the problem and does not have to find the solution. 
I would become too tired because I think a lot... my mind is tired, my body also tired... I feel like running away from home... I could not get my mind straight... I told myself that this is all okay... it's okay... it's okay... this thing is just temporary...

(Subject 2)

While subject 4 mentioned that she thinks a lot to find a solution to the problem. But when she fails to get the solution, she becomes more stressful.

I try to think of what to do... but when I don't see any ways to solve the problem... I become more stressful... everytime I have problem... I would think and think ... to find the solution...

(Subjects 4)

The third subtheme is avoiding problems by doing other activities such as sleeping, watching videos or writing. This had been done by subjects 1 and subjects 2 . This activity is done so that they can forget about the problem. Therefore there is no effort to find solution for the problem. The subjects prefer to keep the problem to themselves and do not want to tell anyone. For instance subject 3 mentioned she would be quiet for a long time and does not want to express her feelings to anyone. Subjects behave like sulky and only hoping the problem is solved by others.

I prefer to keep it... I never express my feelins... when I feel stress I would be quiet... like sulky... I just hope that the problems just settle... I let this to happen for a long time and it became worst... I become sulky more often ...

(Subject 3)

The fourth subtheme is crying. Subject 1 and 2 mentioned that they cry for immediate release from stress.

I usually would cry and just let it be... crying help me to release quickly... I cry and then I try to forget everything...

(Subject 1)

When I'm under too much pressure... I want to be alone and then cry... I cry alone... I need quick release and I can forget about my problem...

(Subject 2)

\section{Coping Mechanism After the Intervention}

The second theme is coping mechanism after going through the counselling intervention. Interviews were conducted after completing the entire session of the counselling intervention. Purposes of the interviews were to obtain information about the coping mechanism among subjects. Based on the transcript analysis, subjects shared various experience after undergone the counselling intervention. However, there is only one emerging theme for coping mechanism after intervention which is calm down. Four subjects $(n=4)$ coped by taking some time to calm their mind and the start to find possible solutions to their problems.

Subject 1 stated that she tried to be calm by relaxing her mind so that she able to view the problem in a more positive way. Then she can be rational and not taking any action in a hurry.

Now I will think deeply before doing something ... like going to calm my mind first ... look at that thing from ... rational ... in another angle ... another angle ... I will not hurry.

(Subject 1) 
The subject 5 and 2 stated that they act by trying to calm their minds before finding a solution. Then after getting a good solution they will solve the problem right away.

I try to calm my mind... then after I feel ok. I think about the solution.

(Subject 5)

I will cool down and go settle the problem... I will calm myself and then solve the problem.

(Subject 2)

Finally, the subject 6 also acted with calmness when distressed. Subjects use spiritual methods such as praying and zikir. Subsequently, the subject stated that she needed support from the person she trusted most. In this way, she will be more confident to solve her problem.

I'm looking for someone to share my problem ... find someone whom I can share ... who can give support to manage the stress ... I do a lot of prayer and zikir... I have to be cool.

(Subject 6)

Based on the emerging theme, it explains that the subject of this study having negative emotional coping mechanism before undergoing the counselling session. Therefore, it does not help the subjects to develop positive attitudes whenever distress occurs. Then this also contributes to the high level of psychological distress among the subjects. After the counselling session, the subject of this study has a better emotional coping mechanism towards psychological distress. Apart from that, the subjects also have different views on psychological distress compared to before the intervention. The process on intervention which took five (5) weeks has succeeded in helping the subject to learn and practice new positive behaviour and thinking.

\section{Discussion}

Pearlin's psychological distress theory stated that psychological distress has four important elements; i) individual characteristics, ii) distress level, iii) social support, iv) coping skill. Based on Lazarus Stress Theory (Lazarus \& Folkman, 1984), there are two types coping mechanism in dealing with distress that are problem-focused coping and emotion-focused coping. These coping strategies have two main roles which are to deals with the problems that cause distress and controlling emotions related to distress.

Based on the findings, the coping mechanism can be described based on two conditions which are before the session and after the session. Before undergoing counseling intervention sessions, subjects tend to have negative coping mechanism such as withdrawal, crying, over thinking and problems avoiding. This kind of negative coping mechanism occurs as the subject focuses only on emotion. As described in Lazarus Stress Theory of emotion-focused coping has several types of coping mechanism such as avoidance, keep distance and acceptance without solving the problems.

After undergoing the counselling sessions the subjects have similarities in terms of new coping mechanism behavioural which is to calm the feelings. In a pleasant emotional state the subject is ready to find a solution to the problem. Then, they also seek the nearest individual support to help the subject to be more confident in solving the problem. This is in line with Lazarus's description of a problemfocused coping strategy which is to understand the problem, find solutions, learn new skills and change behavior. The previous study (Chan, 1998) also found that individuals with a rational mindedness and seeking support showed a more positive change. In addition, the subjects also show changes when practicing new behaviours such as calm down and learn the spiritual methods that helpful in reducing the level of distress. This is supported by previous studies which find that spiritual methods also help in dealing with psychological distress (Salkovsky, Romi, \& Lewis, 2015). 
This study explained the diversity of coping mechanism due to factors such as age differences and the maturity level of the subject. These factors also contributed to the different experiences and changes among subjects who undergo counselling intervention sessions based on solution focused therapy. The subjects who are much older are easier to build rapport with counsellors but take more time to show changes. This is because they have strong principles and values for their lives. Meanwhile, subjects who are young age took more time to build rapport with the counsellor. However, after establishing the relationship the subjects did not take long to show positive changes. Younger subjects tend to refer to the counsellor to understand something that happens in their lives. They often discussed about anything regarding their lives to get counsellor's opinion.

\section{Implication of study}

This study is a small scale qualitative study. Nevertheless, the implementation of this study clearly has a positive implication on the subject involved. This is because the subjects have reduced the level of distress to lower scores after undergoing five sessions of counseling intervention. A more meaningful implication to the subject of study is in terms of having a more positive thinking style and able to practice a more positive emotional coping mechanism when distress occurs. The subjects also managed to understand the psychological distress more clearly in terms of factors, symptoms and methods of control. The most obvious change in the subject of study is in terms of better emotional control. As a result of the counseling intervention session, the subjects have more positive emotions and can stay calm even when they facing a problem.

\section{Conclusion}

The objective of this study is to understand the emotional coping strategies through the Solution Focused Counselling therapy. The result of this study is subjected to the experiences of six subjects who experiencing psychological distress and undergone the counselling intervention based on the Solution Focused Therapy. Therefore, further studies need to be done to look at other individual experiences. In conclusion, solution focused therapy help distressed individuals to have better emotions control. However, continuous guidance and support is also important to help them dealing with psychological distress throughout their life.

\section{References}

Amat Taap Manshor, Fontaine, R., \& Chong Siong Choy. (2003). Occupational Stress Among Managers: a Malaysian Survey . Journal of Managerial Psychology, 622-628.

Azlihanis Abdul Hadi, Nyi Nyi Naing, Aziah Daud, Rusli Nordin, \& Mohd Rahim Sulong. (2009). Prevalence and Factors Associated with Stress Among Secondary School Teachers in Kota Bharu Kelantan, Malaysia. Southeast Asian Journal Med Public Health, 1359-1370.

Bond, C., Woods, K., Humphrey, N., Symes, W., \& Green, L. (2013). Practitioner Review: The Effectiveness of Solution Focused Brief Therapy with Children and Families: A Systematic and Critical Evaluation of the Literature from 1990-2010. Journal of Child Psychology and Psychiatry, 707-723.

Castaldo, D. D. (2008). Divorced, without Children: Solution Focused Therapy with Women at Midlife. USA: Routledge.

Cohen, L., Manion, 1., \& Morrison, K. (2007). Research Methods in Education. USA: Routledge.

Cresswell, J. W., \& Plano Clark, V. L. (2011). Designing and Conducting Mixed Methods Research. Thousand Oaks: SAGE Publications.

Crockett, S. A., \& Prosek, E. A. (2013). Promoting Cognitive, Emotional, and Spiritual Client Change: The Infusion of Solution-Focused Counseling and Ritual Therapy . Counseling and Values, 237-253.

de Shazer, S., \& Dolan, Y. (2007). More than Miracles: The State of the Art of Solution-Focused Brief Therapy. NY: The Hasworth Press. 
Estrada, B., \& Beyebach, M. (2007). Solution-Focused Therapy with Depressed Deaf Persons. Journal of Family Psychotherapy, 45-63.

Faatin Zulaikha Amir, \& Norashikin Mahmud. (2014). Relationship between Discrimination in Career Development and Stress Among Female Workers in Malaysia. Australian Journal of Basic and Applied Sciences, 101-107.

Fisher, J., Astbury, J., de Mello, M., \& Saxena, S. (2009). Mental Health of Women's Reproductive Health: A global review of the literature. Switzerland: World Health Organization.

Jaseem Koorankot, Tilottama Mukherjee, \& Z.A.A. Ashraf. (2014). Solution-Focused Brief Therapy for Depression in an Indian Community: A Pilot Study. International Journal of SolutionFocused Practices, 4-8.

Johnson, S. M. (2009). Attachment Theory and Emotionally Focused Therapy for Individuals and Couples. In J. H. Obegi, \& E. Berant, Attachment Theory and Research in Clinical Work with Adults (pp. 410-433). New York: Guilford Publications.

Kendall-Tackett, K. A. (2005). Caught in the Middle: Stress in the Lives of Young Adult Women. In K. A. Kendal-Tackett, Handbook of Women, Stress, and Trauma (pp. 33-52). New York: Brunner-Routledge.

Lazarus, R. S., \& Folkman, S. (1984). Stress, Appraisal and Coping. New York: Springer Publishing.

Lestari, S. (2000). Psikologi Keluarga:Penanaman Nilai dan Penanganan Konflik dalam Keluarga. Jakarta: Sri Lestari .

Lipchick, E. (2002). Beyond Technique in Solution-Focused Therapy. New York: The Guilford Press.

Miles, M. B., \& Huberman, M. A. (1994). Qualitative Data Analysis. Thousand Oaks: SAGE Publications.

Miller, G., \& de Shazer, S. (2000). Emotions in Solution-Focused Therapy: A Re-examination. Family Process, 5-23.

Miller, G., \& de Shazer, S. (2004). Emotions in Solution-Focused Therapy: A Re-examination. Family Process, 5-23.

Mirowsky, J., \& Ross, C. E. (2003). Social Causes of Psychological Distress. USA: Walter de Gruyter.

Noor Ba'yah Abd Kadir, \& Bifulco, A. (2011). Vulnerability, Life Events and Depression among Moslem Malaysian Women: Comparing Those Married and those Divorced and Separated. Soc Psychiatry Psychiatr Epidemiol , 853-862.

Noor Rahamah Hj Abu Bakar. (2012). Wanita Bekerja dan Pengurusan Keluarga. Malaysia Journal of Society and Space, 155-162.

Noor, N. M. (1999). Roles and Women's Well-Being: Some Preliminary Findings From Malaysia. Sex Roles, 123-145.

Noor, N. M. (2002). Work-Family Conflict, Locus of Control, and Women's Well-Being: est of Alternatives Pathways. The Journal of Social Psychology, 645-662.

Noor, N. M. (2003). Work- and Family- Related Variables, Work- Family Conflict and Women's Well- Being: Some Observations. Community, Work and Family, 297-319.

Pashapu Dharma Reddy, Ammapattian Thirumoorthy, Poreddy Vijayalakshmi, \& Mohammed Ameer Hamza. (2017). Effectiveness of Solution-Focused Brief Therapy for an Adolescent Girl with Moderate Depression. Indian Journal of Psychological Medicine, 87-89.

Pearlin, L. I. (1989). The Sociological Study of Stress. Journal if Health and Social Behaviors, 241256.

Rubin, H. J., \& Rubin, I. S. (1995). Qualitative Interviewing: The Art of Hearing Data. San Diego: Sage Publications.

Salkovsky, M., Romi, S., \& Lewis, R. (2015). Teacher's Coping Styles and Factors Inhibiting teacher's Preferred Classroom Management Practice. Teaching and Teacher Education, 56-65.

Silverman, D. (2010). Doing Qualitative Research. London: SAGE Publications.

Simon, R. W., \& Nath, L. E. (2004). Gender and Emotion in United States: Do Men and Women Differ in Self-Reports of Feelings and Expressive Behavior? American Journal of Sociology, 1137-1176.

Sklare, G. B. (2005). Brief Counseling That Works. Thousand Oaks, California: Corwin Press.

Smock, S. A., Trepper, T. S., Wetchler, J. L., McCollum, E. E., Ray, R., \& Pierce, K. (2008). Solution-Focused Group Therapy for Level 1 Substance Abusers. Journal of Marital and Family Therapy, 107-120. 
Umi Adzlin S, Marhani M, Salina AA, Ruzanna ZamZam, Rosdinom Razali, Rozhan Sharif MR, \& Azrul Rozaiman A. (2011). Prevalence of Psychological Distress and Depressive Disorders among Married Working Women in Malaysia. Malaysian Journal of Psychiatry, 2-5.

Yin, R. K. (2014). Case Study Research Design and Methods. Thousand Oaks: SAGE Publications. 